\title{
High voltage power supply controller for Electrostatic precipitators
}

\author{
Beula David $^{1}$, Indira Megaravalli Shankarappa ${ }^{2}$, Balaji Nerayanur ${ }^{3}$ \\ ${ }^{1}$ Department of Electrical and Electronics Engineering, Sir. M. Visvesvaraya Institute of Technology, Bangalore, India \\ ${ }^{2}$ Department of Electrical and Electronics Engineering, M.S. Ramaiah University of Applied Sciences, Bangalore, India \\ ${ }^{3}$ Department of Electrical and Electronics Engineering, Dayananda Sagar College of Engineering, Bangalore, India
}

\begin{abstract}
Article Info
\section{Article history:}

Received Jul 13, 2021

Revised Jan 25, 2022

Accepted Jan 31, 2022

\section{Keywords:}

Collection efficiency Current-fed push-pull DC power supply Electrostatic precipitators Spark and arc control

ABSTRACT

Gaseous exhausts from various industries pollute the environment with flyash generally filtered by electrostatic precipitators (ESPs) before being released to the atmosphere. This paper presents the development of a controller for ESP power supply. The controller maintains the voltage applied to ESP at its maximum average value by duty cycle control that results in an improvement in dust collection-efficiency. The limiting factor for the output voltage is the breakdown of gas (spark/arc) in the electrode gap of ESP. During a spark/arc condition, the duty cycle limit imposed by the controller causes a reduction in output voltage that leads to the prevention of spark/arc. The present design has a response faster than line frequency power supply controllers. The control circuit is simpler, easy to implement and uses a standard PWM controller IC. The design of power stage uses a flyback current-fed push-pull DC-DC converter with multiple secondary circuits, which has the advantages of instantaneous current limit and less voltage stress on rectifier-diodes. Simulation is performed to obtain a $1 \mathrm{kV}, 100 \mathrm{~W}$ output from a $24 \mathrm{VDC}$ source. The results are compared with experimental values to validate the controller's ability to achieve good load regulation during normal operation and a reduction in output voltage during spark/arc condition.
\end{abstract}

This is an open access article under the CC BY-SA license.

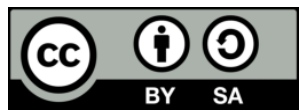

\section{Corresponding Author:}

Beula David

Department of Electrical and Electronics Engineering, Sir M Visvesvaraya Institute of Technology,

Bangalore- 562 157, Karnataka, India

Email: beula.d2014@gmail.com

\section{INTRODUCTION}

The major source of environmental pollution is fly-ash (dust) particles from various industries and power plants. Government regulatory bodies have made extraction of fly-ash particles from industrial flue gases mandatory before they are released into the atmosphere. Electrostatic precipitators are used to filter flyash particles by ionizing them in a high electric field. A typical electrostatic precipitator (ESP) consists of a discharge electrode that is negatively charged and the other, a grounded collecting electrode. A high voltage is applied between these electrodes to initiate a corona discharge to ionize the dust particles. The charged dust particles get deposited on the collecting electrodes. They are periodically dislodged by rapping the electrodes and are collected in dust hoppers to be removed. ESP power supplies in the range of $10-100 \mathrm{kV}$ are used in incinerators, biomass plants, power plants and process industries to name a few. In many smallscale ESPs use high voltage power supplies of few hundred watts also [1].

ESP power supplies used in large industries are thyristor-controlled, operating at line frequency. They are plagued with low average DC output due to line frequency operation, high percentage ripple, large 
size of the input inductor and high voltage (HV) transformer. The primary inductor limits the current during a short circuit on the load side. The output voltage and spark/arc between electrodes are controlled by an automatic voltage controller (AVC) that reduces the applied voltage based on the feedback signals from both load and supply sides. The controllers used in line frequency power supplies are sluggish in nature and the minimum response time of controller is $10 \mathrm{~ms}$ to adjust the output [2]. Development of new power devices led to the use of IGBT based high frequency power supplies for ESP's. These have a low ripple output voltage with a good average value that results in better collection efficiency and fast control during flashover [3], [4]. Another commonly used power converter topology for operation at high frequency is a series-parallel resonant converter that is compact, with a better transient response and higher efficiency [5]-[8]. Further improvement in the power converter is in terms of optimization in the design of HV transformers [9]-[12]. Generally, these converters use digital controllers to regulate the output voltage and detect faults through the measurement of output voltage or current using sensing circuits. Different control algorithms are implemented to extinguish the spark/arc [13]-[15]. In general, power supply controllers vary in their sensing of the control parameters, their implementation of control circuits to maintain the maximum average output voltage and spark/arc control.

Apart from large industrial applications, small size ESPs are used in the removal of particulate matter emitted from the combustion of wood in biomass plants, soot particles produced during the drying of rubber and smoke particles generated from combustion of waste in municipal/medical incinerators. In some of the small-sized ESP power supplies, the high voltage DC is obtained by stepping up low voltage AC into high voltage using high voltage transformer and rectification. According to the literature, these are not equipped with any power supply controllers [16], [17]. Another configuration used in small size ESP power supplies is series resonant converters with digital controllers [18]. For the control of the system, a digital signal processor with appropriate peripherals and analog signal acquisition are used. Therefore, it is quite challenging to select an appropriate power circuit topology and design of a power controller to maintain a maximum average output voltage to increase collection efficiency and proper control of spark/arc conditions.

This paper presents a development of a controller for small scale ESP power supply applications to improve performance during normal operation and provide good control during spark/arc operation. The power stage is designed using a flyback current-fed push-pull DC-DC converter with multiple secondary circuits and operating at high frequency. As the power converter is current fed in nature it is easier to limit current during short circuit at load side. The rectifier components on the high voltage side are subjected to less voltage stress due to multiple secondary windings at lower voltage levels. The proposed controller maintains maximum average output voltage by regulating the output against the variation in load, using duty cycle adjustment. A new scheme has been devised to control the output of the power supply during spark/arc condition. When there is a spark at load, the controller puts a limit on the duty cycle and hence the output voltage starts reducing, by dropping the voltage across the input inductor. If there is a permanent short at the output due to an arc, the total source voltage drops across the input inductor, so that power delivered to the load reduces drastically. This control scheme is designed using a common PWM IC and easily implemented compared to other controllers. The high frequency of operation makes the control action faster than the line frequency controller. The usual power output level of the converter used is $1-2 \mathrm{~kW}$ that makes it suitable for small scale ESP power supply applications [19].

\section{RESEARCH METHOD}

In an ESP, it is necessary to apply high voltage DC to produce strong electric field strength between collection and discharge electrodes. The electrical characteristics of an ESP show that the power supply must be operated close to the point of Vspark voltage for better collection efficiency, and there are frequent short circuits at the load due to the accumulation of dust particles in the electrodes. Therefore, a power supply controller is necessary for the power supply. This paper has arrived with control characteristics to meet the requirements of the power supply. The power supply controller is implemented to achieve maximum collection efficiency during normal operation and good control during spark and arc conditions.

\subsection{Power converter configuration}

The power converter used in the power supply is shown in Figure 1. The DC input voltage is $V_{i n}$. The flyback transformer primary $L_{i p}$ connected in series with the push-pull converter behaves as an input inductor. The flyback secondary $L_{i s}$ is connected back to input. The inductors $L_{p 1}$ and $L_{p 2}$ form two primaries of the push-pull transformer, while $L_{s 1}$ to $L_{s n}$ form the ' $n$ ' secondary windings. The secondary voltage is rectified using diodes $D_{11}$ and $D_{21}$ and doubled by charging capacitors $C_{11}$ and $C_{21}$ coming in series. Pushpull switches $S_{1}$ and $S_{2}$ are designed to operate in a non - overlapping mode. Therefore, the center-tap voltage of push-pull transformer $\left(V_{c t}\right)$ is lower than the DC input voltage $\left(V_{i n}\right) . \mathrm{V}_{\mathrm{G} 1}$ and $\mathrm{V}_{\mathrm{G} 2}$ are the gate signals 
applied to switches $S_{1}$ and $S_{2}$ respectively. The output voltage $\left(V_{o}\right)$ is realized by multiple secondary circuits connected in series. Resistance $R_{L}$ represents the non-linear load of ESP, and the resistance depends on the concentration of particles in the flue gas and the resistivity of the particles. The converter must operate in discontinuous mode at all load conditions that necessitates non-overlapping of power switches.

Converter operates in four modes in each switching cycle:

Mode 1: With $\mathrm{S}_{1} \mathrm{ON}$ and $\mathrm{S}_{2} \mathrm{OFF}$, current flows through the primary circuit of flyback $\left(L_{i p}\right)$ and push-pull $\left(L_{p 1}\right)$, transferring the energy from source to load.

Mode 2: When $S_{1}$ is OFF with $S_{2}$ being OFF, diode $D_{3}$ is $\mathrm{ON}$ and flyback secondary transfers energy to the input.

Mode 3: When the switch $\mathrm{S}_{2}$ is $\mathrm{ON}$ and switch $\mathrm{S}_{1}$ is OFF, current flows through the primary circuit of flyback $\left(L_{i p}\right)$ and push-pull $\left(L_{p 2}\right)$, and energy is transferred from source to load.

Mode 4: When $S_{2}$ is OFF, with switch $S_{1}$ being OFF, diode $D_{3}$ is $O N$ and flyback secondary transfers energy to the input.

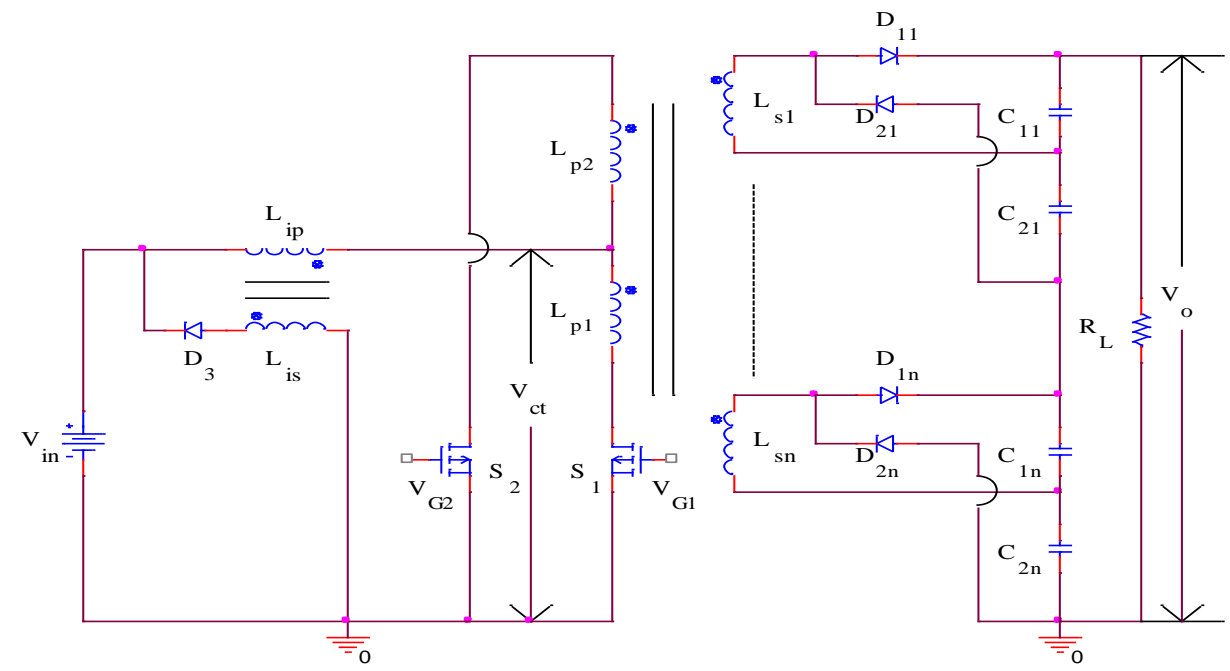

Figure 1. Power converter circuit

This converter configuration has some advantages when it is designed for an ESP power supply application. In general, as the load on ESP is subjected to frequent short circuits, a current-limiting inductor is provided in the primary circuit of conventional line-frequency ESP power supplies. In this topology, the inductance of the flyback transformer functions as a current limiting inductor. As the secondary of the flyback is connected to the source and the converter is operated in discontinuous mode, the stored energy is completely fed back to source. That enhances the operating efficiency. Even though there are multiple secondary windings, only one inductor in the primary circuit is sufficient due to the current-fed configuration. Higher voltages can be easily obtained by inserting additional secondary circuits based on the requirements of the application. The circuit is simple in construction with a less number of components.

\subsection{Electrical characteristics of an ESP}

The current-voltage characteristic of an ESP is shown in Figure 2. A corona discharge is initiated when the applied voltage reaches $V_{\text {onset }}$. The resulting corona current between the electrodes increases steeply with applied voltage [20], [21]. As the distance between the electrodes is fixed for a given precipitator, the corona develops into a spark discharge when the peak voltage exceeds maximum withstand voltage $\left(V_{\text {Spark }}\right)$ of the dust medium. A spark/arc discharge that appears between the electrodes is due to change in process parameters like gas and dust particles [22]. On occurrence of a spark discharge, the controller lowers the ESP voltage that automatically extinguishes the spark and maintains normal voltage aftermath. There is a temporary reduction in the efficiency of dust collection at the instant of the spark. An arc discharge is more intense than a spark and exists for a longer duration. The arc not being able to self-extinguish damages the electrodes and the power circuit experiences high stress. The supply to the field is cut off immediately for a few cycles to interrupt arc currents. The strength of the charge acquired by dust particles due to corona discharge depends on the maximum value of the applied voltage. The dust particles acquire a charge of $q$ and hence experience a force $F=q E$. This force drives them towards the collecting plates. The particle migration velocity $\left(V_{e}\right)$ is given by the relation [23]. 


$$
\mathrm{V}_{\mathrm{e}}=\frac{\mathrm{qEC}}{3 \pi \mu \mathrm{D}_{\mathrm{p}}}
$$

where, $q$ - theparticle charge, $E$ - the average electric field, $\mu$ - gas viscosity, $D_{p}$ - particle diameter and $C$-slip correction factor. The migration velocity of the particles can be increased with an applied voltage close to $V_{\text {Spark. }}$ The collection efficiency [24], [25] of ESP is given by (2).

$$
\eta=e^{\frac{-A_{c} \times V_{e}}{Q}}
$$

The (2) is known as the Deutsch-Anderson equation. $A_{c}$ is the electrode's collection area in $\mathrm{m}^{2}$ and $\mathrm{Q}$ is the gas flow rate in $\mathrm{m}^{3} / \mathrm{s}$. Collection efficiency can be enhanced with an increase in migration velocity. For efficient operation of ESP, the power supply must provide maximum average voltage during variable load conditions and reduced voltage under spark conditions to extinguish the spark, which, if uncontrolled, develops into an arc discharge. Hence, it is necessary to have a power supply controller in an ESP.

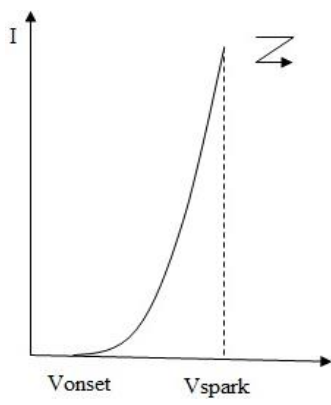

Figure 2. Electrical characteristics of an ESP

\subsection{Controller characteristics}

The controller is designed to satisfy the electrical characteristics of ESP. The first objective of the controller is to maintain a maximum average output voltage for a variation in load, to drive a sufficiently high corona power. The second objective is an instantaneous decrease in output voltage during a spark and reducing power output during an arc condition. The characteristics of the controller are shown in Figure 3. The input voltage to the power converter is $V_{i n}, V_{p 1}$ and $V_{i p}$ are the voltages across the push-pull transformer primary winding $\left(L_{p l}\right)$ and flyback transformer primary winding $\left(L_{i p}\right)$ respectively. The voltage across one of the secondary of the push pull transformer is $V_{s}$. Current through the load resistance $\left(R_{L}\right)$ is $I_{L}$ and the rated current of the converter is $I_{R}$. The concentration of dust particles in flue gases, keeps changing, causing changes in resistance. A low concentration of dust particles in the flue gas is considered as a no-load current condition and a high concentration of dust particles as a rated current condition. The current above rated value is considered as reduction in dielectric strength of the medium and is indicated as a spark discharge condition. The permanent breakdown of the dielectric strength of medium is the arc discharge condition. The operation of the controller can be divided into three sections.

\subsubsection{Normal operating condition $\left[0-\mathbf{t}_{1}\right]$}

The load current varies due to changes in resistance of the dust particle concentration. The duration between $0-\mathrm{t}_{1}$, denotes normal operation and the load current varies from no-load value to rated current. Referring to Figure 3, the input voltage $V_{\text {in }}$ is assumed to remain constant and the increase in load current makes the voltage across flyback primary winding $V_{i p}$ to increase. That makes the voltage across the pushpull primary $V_{p 1}$ decrease. The output voltage is regulated by modulating duty ratio of switches $S_{1}$ and $S_{2}$ to compensate for variations in load. The feedback loop senses $V_{o}$ and controls the ON time of the switches to maintain a constant output voltage. Therefore, the secondary voltage $V_{s}$ of the push-pull also remains constant during this interval. Maximum output voltage is obtained for any variation in load that leads to higher dust collection efficiency.

\subsubsection{Spark discharge condition $\left[\mathbf{t}_{1}-\mathbf{t}_{2}\right]$}

The duration between $t_{1}-t_{2}$, is the period when the load current is higher than the rated current. That is considered as spark discharge condition. The input voltage $V_{\text {in }}$ is assumed to remain constant. As the duty 
cycle is limited, for any increase in load current, the voltage drops across flyback primary winding increases. This reduces the drop across the push-pull primary that makes $V_{s}$ decrease, thus output voltage decreases. The instantaneous reduction in output voltage enables an increase in the dielectric strength of the gap that suppresses the spark instantly.

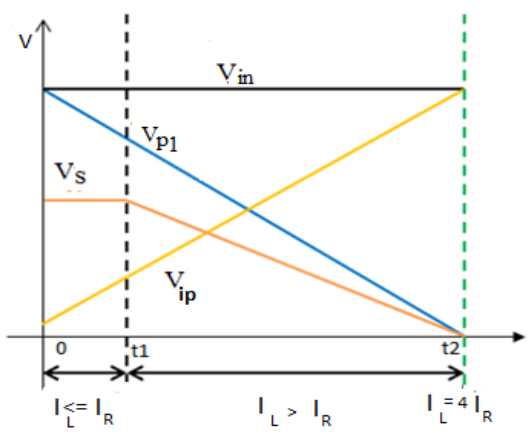

Figure 3. Characteristics of controller

\subsubsection{Arc discharge condition $\left[A t t_{2}\right]$}

A sustained spark is considered as an arc (permanent short) condition and the instant is denoted as $\mathrm{t}_{2}$. At this instant, the entire input voltage is dropped across the flyback primary winding. This makes $V_{p l}$ drop to a low value, driving $V_{s}$ and output voltage also to a low value. The drastic reduction in output to the load reduces damage to the electrodes and protects the power supply circuit.

\subsection{Block diagram of power supply controller}

A block diagram representation of power supply controller is given in Figure 4. The feedback voltage $\left(V_{F B}\right)$ from the output of the power supply is compared with a stable reference voltage $\left(V_{R e f}\right)$ to produce a voltage error signal $\left(V_{e}\right)$. The output of the error amplifier $\left(V_{c}\right)$ is converted to a duty cycle by the pulse width modulator that drives the MOSFET switches. A type 3 compensated error amplifier is used to compensate for the voltage feedback loop and produce the best transient response. Maximum pulse width is derived based on regulating the output voltage at rated current. During a spark/arc condition, the pulse width limit imposed by the duty cycle limit circuit provides an additional control input to PWM. The output voltage is not regulated because of the pulse width limit imposed by the controller, thereby reducing the voltage applied to the load. During an arc condition, the total input voltage drops across the primary of the flyback transformer and the load current is limited to four times the rated load current, leaving very low power to load. Hence there is no requirement for additional circuits to detect the spark, as in a conventional controller circuit.

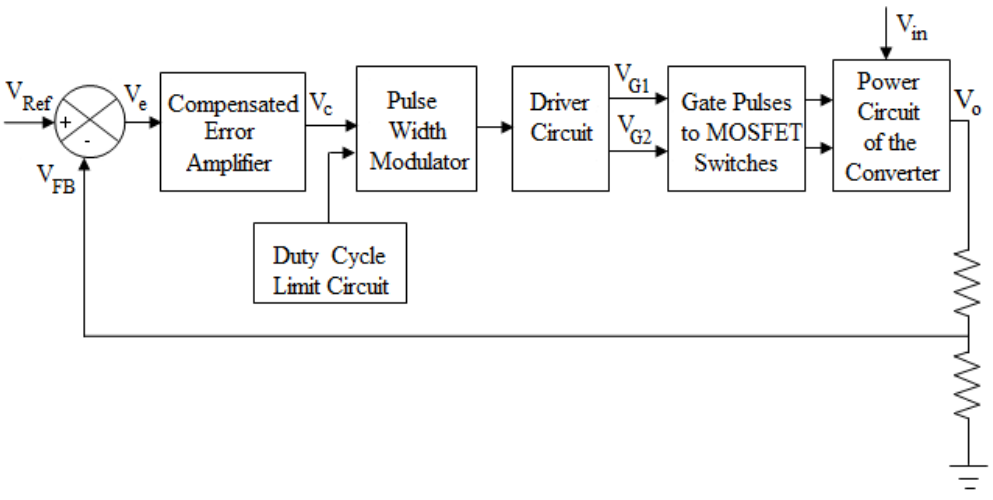

Figure 4. Block diagram of power supply controller 


\section{RESULTS AND DISCUSSION}

The controller is designed for the power supply with an output voltage of $1 \mathrm{kV}$ and a current of $100 \mathrm{~mA}$ from a 24VDC input. The switching frequency is considered to be $20 \mathrm{kHz}$. The inductance of flyback primary is calculated by considering drop across it, is $25 \%$ of the source voltage and the remaining $75 \%$ drop across the primary of the push-pull transformer. The DC voltage is converted into high-frequency pulses at the primary of the converter transformer using power semiconductor switching devices. The turns ratio of the push-pull transformer is selected such that $250 \mathrm{~V}$ is obtained across the secondary. The secondary voltage is rectified and given to a voltage doublers circuit to boost to a value of $500 \mathrm{~V}$. The two secondary circuits are connected in series to provide an output voltage of $1 \mathrm{kV}$. The push-pull converter operates in a non-overlapping discontinuous current mode with a maximum duty ratio of $34 \%$. The designed values of flyback primary inductance, push-pull primary/secondary inductance and output capacitance are $7 \mu \mathrm{H}$, $126 \mu \mathrm{H} / 24 \mathrm{mH}$ and $1.6 \mu \mathrm{F}$ respectively. The K-factor method is used for the design of type 3 compensated error amplifier.

\subsection{Simulation results}

The closed loop operation of the converter is simulated using PSPICE. Ideal power switches and ideal diodes are used in the simulation. The simulation circuit of power supply controller is shown in Figure 5. The results of the simulation are presented for the normal, spark and arc conditions.

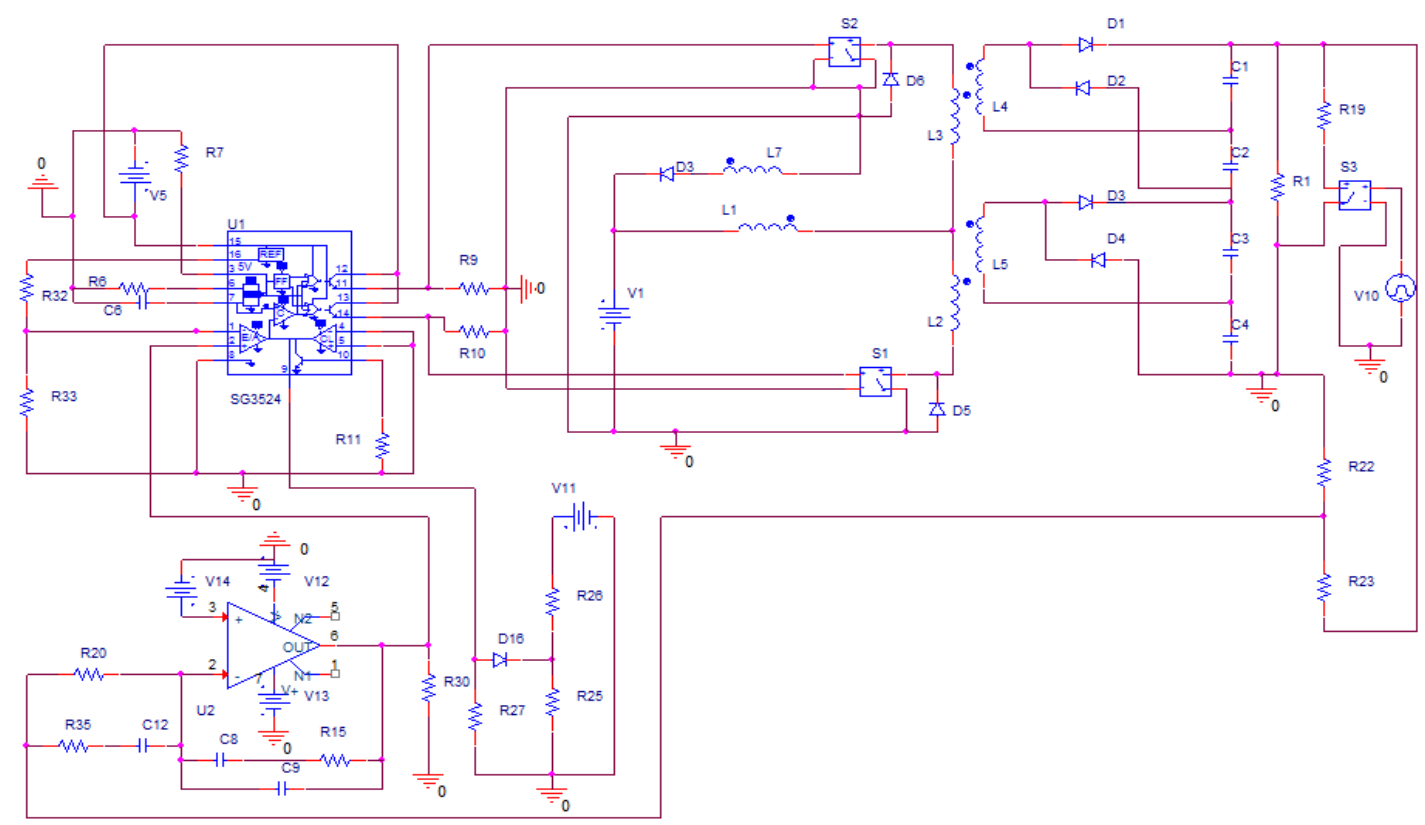

Figure 5. Simulation circuit of power supply controller

Normal operating condition: closed loop simulation is carried out for various load current ranging from $10 \%$ to $100 \%$ to verify the behavior of the controller during the period $0-\mathrm{t}_{1}$. When the load current varies from $10 \%$ to $100 \%$ of rated current, there is an increase in duty cycle from $14 \%$ to $34 \%$ and the output voltage is maintained constant at $960 \mathrm{~V}$. The variation in duty cycle, for different values of load current is plotted and is given in Figure 6. This indicates that for any variation in load current from no-load to rated load, modulation in duty cycle regulates the output voltage. Waveforms at rated load condition are shown in Figure 7. Top trace shows the pulse width has increased to $17 \mu \mathrm{s}$, which corresponds to $34 \%$ of duty cycle at full load. The bottom trace shows the increase in input current at full load condition, and the current is discontinuous. The current starts from zero and increases linearly, reaching a peak of $16.6 \mathrm{~A}$ during on-time of the switch. The middle trace shows the voltage has dropped to $6.6 \mathrm{~V}$ across the primary of a flyback transformer that is close to $25 \%$ of input voltage. Waveforms of current through the flyback primary winding and voltage across it under no-load conditions are shown in Figure 8. At no-load, the pulse width is reduced to a minimum value of $7 \mu$ s that is $14 \%$ of duty cycle. A discontinuous mode of operation is realized, and the peak current at the end of on-time is $6.4 \mathrm{~A}$. The middle trace shows the voltage has dropped to $6.5 \mathrm{~V}$ across the flyback primary winding. 
The transient response of the output voltage during a step change from full load to no-load is shown in Figure 9. Full load is maintained for $10 \mathrm{~ms}$ and is suddenly reduced to no-load for $30 \mathrm{~ms}$. The performance of the control circuit is stable, with output voltage being maintained at a constant value of $960 \mathrm{~V}$. The result indicates that a little fine turning the controller parameter is required to get the desired output voltage. The settling time of output voltage is $3.8 \mathrm{~ms}$ and peak over-shoot is $3.1 \%$.

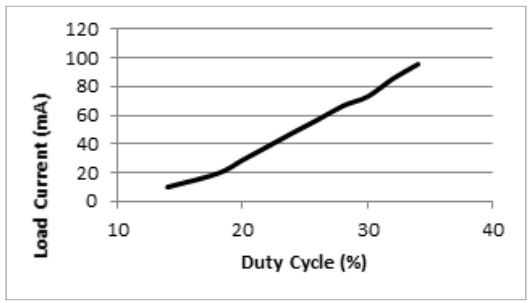

Figure 6. Variation in duty cycle for variation in load current
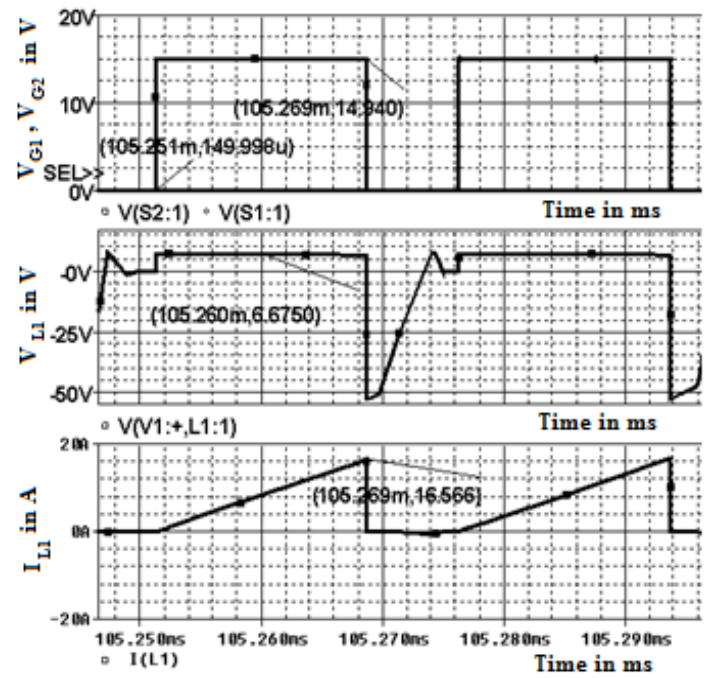

Figure 7. Waveforms at rated-load condition: top trace: gate signals of $S_{1}$ and $S_{2}$, middle trace: voltage across flyback primary, bottom trace: flyback primary current
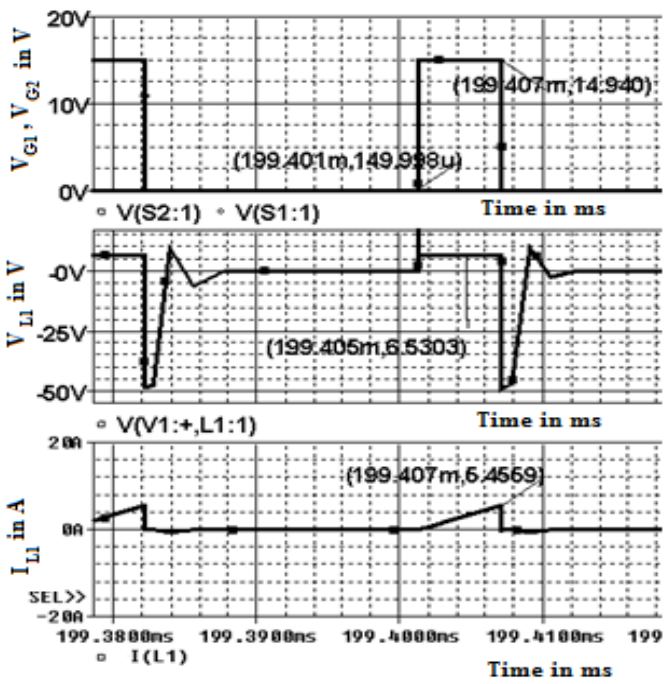

Figure 8. Waveforms at no-load condition: top trace: gate signals of $\mathrm{S}_{1}$ and $\mathrm{S}_{2}$, middle trace: voltage across flyback primary, bottom trace: flyback primary current 


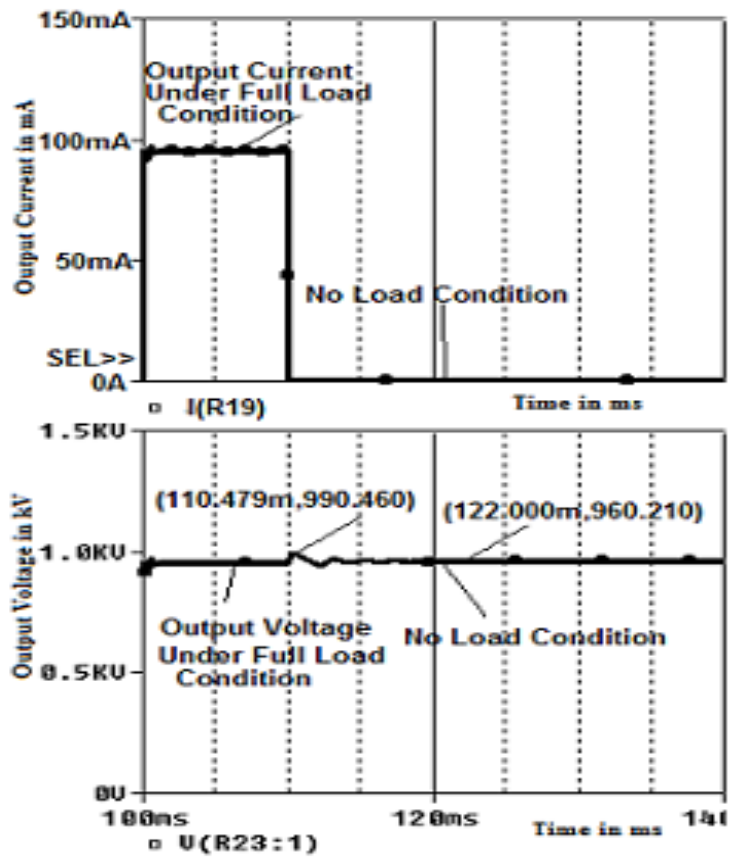

Figure 9. Response for a step change in load, top trace: output current, bottom trace: output voltage

Spark discharge condition: the second objective of the controller is to reduce the output voltage during a spark condition that is verified through simulation. Any increase in load current above rated current increases the drop across the primary winding of the flyback transformer due to the limited duty cycle, maintained at $34 \%$. As the duty cycle is limited by the control circuit, there is simultaneous reduction in output voltage, due to increase in drop across the input inductor. When load current is increased above rated current, there is a proportional reduction in voltage at the output and an increase in voltage across the primary of flyback transformer, as shown in Figure 10.

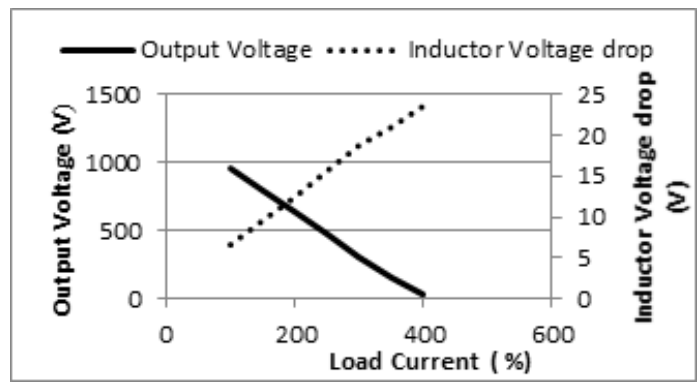

Figure 10. Output voltage and voltage drop across flyback primary for load current variation above rated current

Arc condition: simulation has been performed to verify the operation of the controller during an arc condition and the recovery of output voltage after a breakdown of gas. This condition is simulated by shortcircuiting the load for $10 \mathrm{~ms}$ and then changing the load into a no-load condition for the remaining duration. The voltage drop across the flyback primary winding is increased to $22.9 \mathrm{~V}$ that is close to the total input voltage. The maximum duty cycle is maintained at $34 \%$ by the controller. Simulation results shown in Figure 11 , verify that the output voltage is reduced to a very low value of $35 \mathrm{~V}$ during arc due to the limitation of duty cycle, and the controller is able to recover the output voltage to a maximum value of $959.581 \mathrm{~V}$ when changed to a no-load condition. This proves that the controller operates as per the design and meets the requirements of the load under all three operating conditions. 


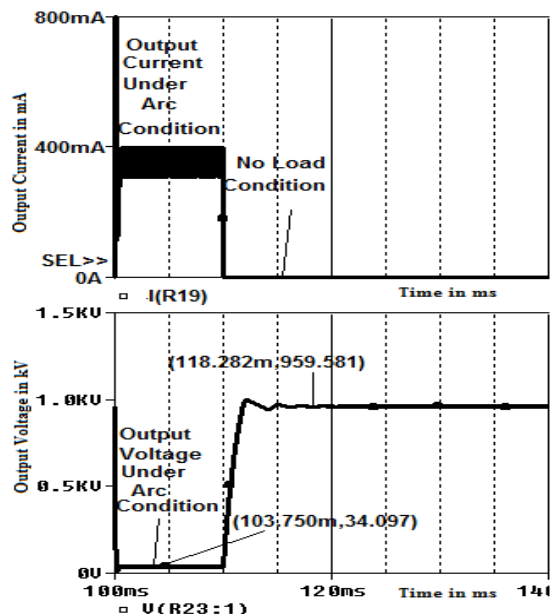

Figure 11. Output of converter with sudden change in load condition, bottom trace: output voltage, top trace: output current

\subsection{Experimental results}

The hardware model of power supply with controller is developed for the output voltage of $1 \mathrm{kV}$, $100 \mathrm{~mA}$ operating at $20 \mathrm{kHz}$ switching frequency. The hardware model, input current, output voltage and current waveforms are shown in Figures 12 (a)-(d).

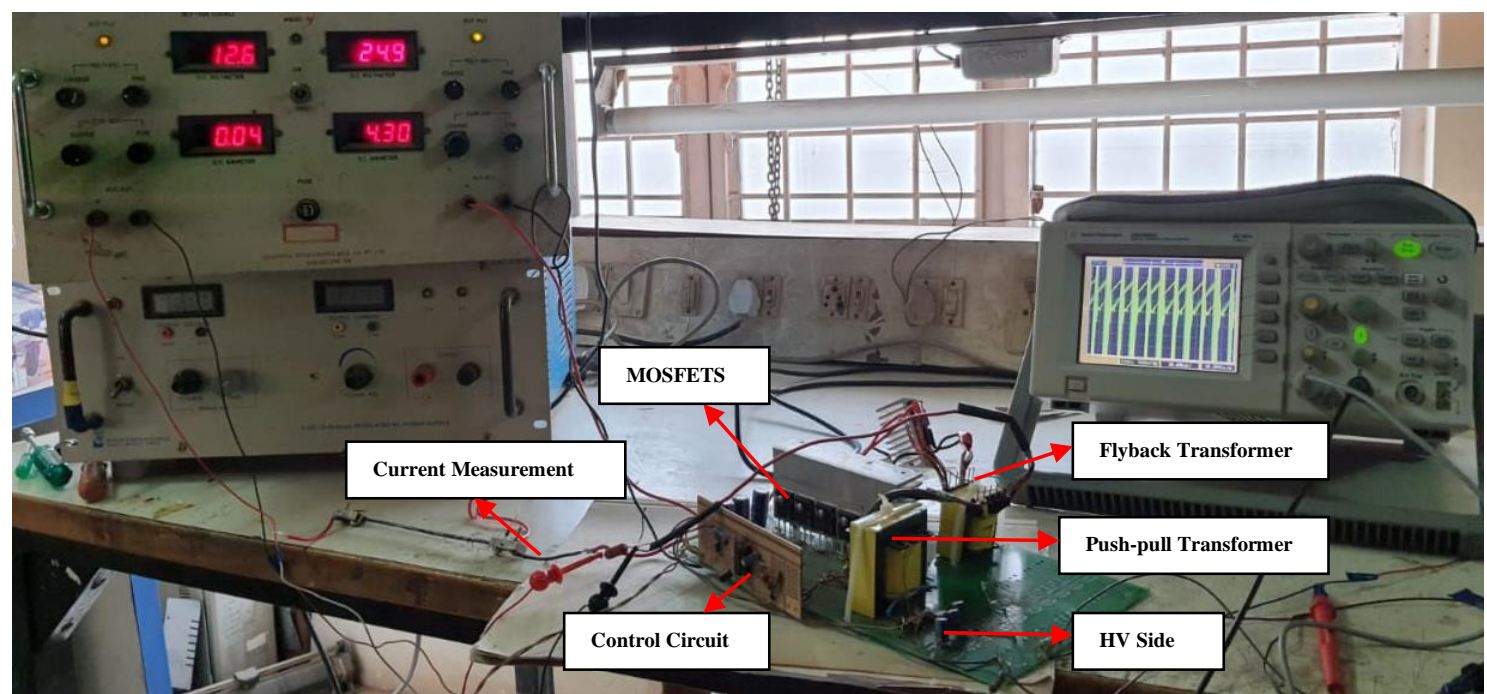

(a)

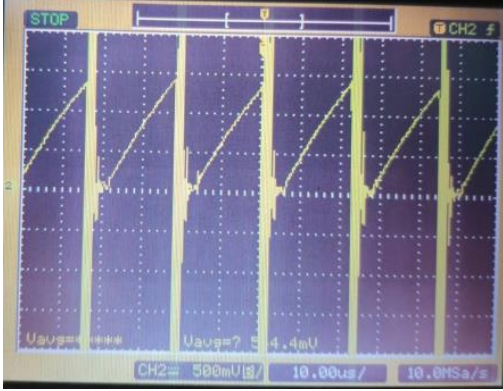

(b)

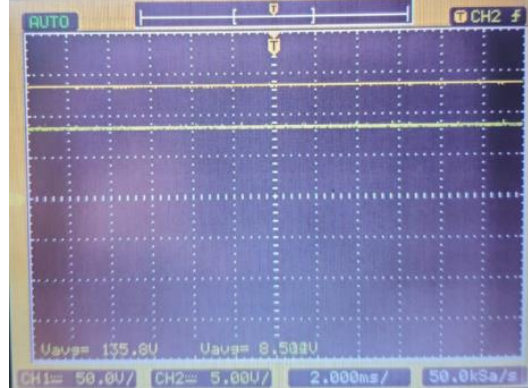

(c)

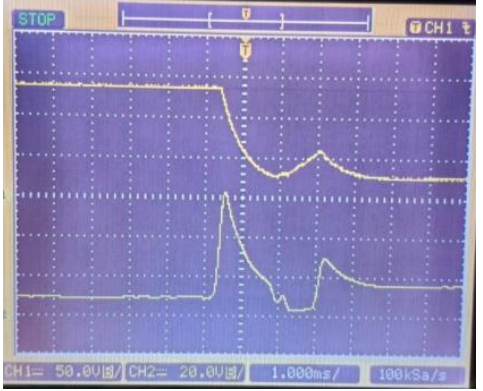

(d)

Figure 12. Power supply module and experimental results (a) hardware model (b) Input current, (c) CH1 is output voltage and $\mathrm{CH} 2$ is output current at rated condition and (d) output voltage and current response under sudden increase in load current 
The input to the converter is given from a DC power supply. IRF260 MOSFETs are used as power switches. The push-pull transformer is built with an E core of E55/21/27, a fly back transformer with an E42/21/20 core, and rectifier circuits with fast recovery diodes. For high voltage transformer, Kapton is used as insulation, and the core is selected to have enough space to accommodate a sufficient layer of insulation. The power input to the PWM IC (SG 3524) is also provided from the DC source. Output is sensed through a voltage divider circuit and the feedback voltage is fed to an error amplifier provided with type3 compensation. The pulse width modulation IC, SG3524, generates the required pulse by comparing the error signal with the ramp. Additional control for duty cycle limit is provided by the 'COMP' pin of the PWM IC. IR2110 is used for MOSFET drivers. High wattage resistors are used to test various load conditions. An oscilloscope is used to record input current, output voltage, and currents at rated load conditions. The input current measurement is done by measuring the voltage drop across resistance of $0.1 \Omega$, inserted in the current path. The peak voltage observed on the oscilloscope is $1.4 \mathrm{~V}$. This corresponds to a peak current of $14 \mathrm{~A}$ and the device $\mathrm{ON}$ time is $16 \mu \mathrm{s}$. The output voltage is measured using a divider with a ratio of 0.143 and the measured voltage is $948 \mathrm{~V}$. Figure 12 (d) shows the output voltage and current waveforms recorded when a sudden increase in current from the rated value. The output voltage was reduced for the increase in current and stabilized in $3.8 \mathrm{~ms}$.

The simulation and experimental results under normal, spark/arc conditions are presented in Table 1. The plots of experimental and simulated results of output voltage are shown in Figure 13. The output voltage remains at its maximum value, which indicates that the controller regulates the output during normal operation. When load current is higher than the rated current, output voltage is reduced. The deviation in output voltage from the designed value shows that a small correction in duty ratio is required. The difference between the designed value of the output voltage and the practical value is due to circuit parasitic. Above rated current, output is not regulated because of limited pulse width by the controller and voltage gets reduced.

The advantage of this approach in the power stage is that it has a high-voltage transformer with multiple secondary windings that have a lower turns ratio compared to a single secondary, and the inductor on the input side is better for limiting current at the load during a short circuit. The existing approach uses a transformer with a single secondary of high turns ratio that leads to a comparatively high leakage inductance. As compared to other controllers, the proposed control scheme is implemented using simple PWM controller. The results obtained by this controller during a sudden change in load show that it is faster than the line frequency power supply controller.

Table 1. Simulation and experimental results of output voltage

\begin{tabular}{cccc}
\hline \multirow{2}{*}{ Load in \% of rated current } & \multicolumn{2}{c}{ Output voltage (in Volts) } & \multirow{2}{*}{ Operating conditions of controller } \\
\hline 10 & 960 & 948 & Normal condition \\
20 & 960 & 948 & \\
30 & 960 & 948 & \\
40 & 960 & 948 & \\
50 & 960 & 948 & \\
60 & 960 & 948 & \\
70 & 960 & 948 & \\
80 & 960 & 948 & \\
90 & 960 & 948 & \\
100 & 960 & 940 & \\
150 & 789 & 660 & \\
200 & 633 & 510 & \\
250 & 466 & 350 & Arc condition \\
300 & 304 & 210 & \\
350 & 156 & 92 & \\
400 & 38 & 20 & \\
\hline
\end{tabular}

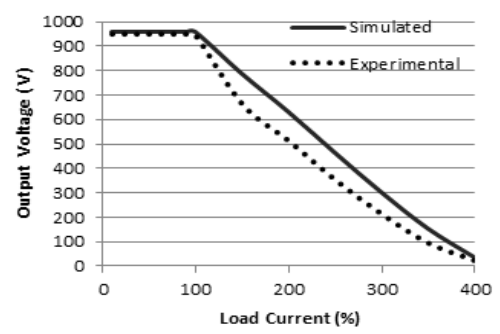

Figure 13. Output voltage for normal, spark and arc conditions 


\section{CONCLUSION}

A high voltage power supply controller is simulated and experimentally validated for an output of $1 \mathrm{kV}$ and $100 \mathrm{~mA}$. Simulation results show the power supply controller maintains an average output voltage of $960 \mathrm{~V}$ by modulating the duty ratio under variable load conditions. For a step change in load, output reaches steady state at $3.8 \mathrm{~ms}$ and the peak overshoot is $3.1 \%$ verifying that the controller is stable. During spark condition, the simulation and experimental results show that there is an instantaneous reduction in output voltage due to the duty cycle limit imposed by the controller. When there is a permanent short circuit due to arc, $95 \%$ of input voltage drops across the primary of flyback transformer and the current is limited to 4 times the rated current. Simulation and experimental results revealed that maximum voltage is maintained under normal operation and spark/arc conditions are well controlled, but there is a difference of about $5 \%$ in experimental results compared to simulation. Proposed controller is faster than line frequency power supply controller; implementation is simple and does not require additional spark/arc detection circuitry as compared to other controller used in ESP power supplies. The converter topology used in this research has a typical power output of a few $\mathrm{kW}$, which limits its applicability in small-scale ESP power supplies.

\section{REFERENCES}

[1] T. Fischer, N. GraB, N. Zouzou, L. Dascalescu, R. Greil and N. Hopf, "Smart Home Precipitator for Biomass Furnaces: Design Considerations on a Small-Scale Electrostatic Precipitator," IEEE Trans. on Industry Applications, vol. 50, no. 3, pp. 2219-2224, Jun. 2014, doi: 10.1109/TIA.2013.2288430.

[2] P. Alto, "State-of-the-Art Electrostatic Precipitator Power Supplies," EPRI, California, 2003, 1008028

[3] S. Vukosavić, "High Frequency Power Supply for Electrostatic Precipitators in Thermal Power Plants," ELECTRONICS, vol. 15, pp.11-20, Jun. 2011.

[4] J. D. Zhu, J. Liang, Y. Lua, and C.H. Zhang, "A new IGBT control and drive circuit for high-power full-bridge inverter for electrostatic precipitators," Journal of Electrostatics, vol.71, pp. 235-239, Jun. 2013, doi: 10.1016/j.elstat.2012.11.025.

[5] T. B. Soeiro, J. Muhlethaler, J. Linner, P. Ranstad, and J. W. Kolar, “Automated Design of a High-Power High-Frequency LCC Resonant Converter for Electrostatic Precipitators," IEEE Trans. on Industrial Electronics, vol. 60, no. 11, pp. 4805-4819, Dec. 2013, doi: 10.1109/TIE.2012.2227897.

[6] S. N. Vukosavić, L. S. Peric, and S. D. Susic," A Novel Power Converter Topology for Electrostatic Precipitators," IEEE Transactions on power Electronics, vol. 31, pp. 152 - 164, Jan 2016, doi: 10.1109/TPEL.2015.2405471.

[7] S. Fan, Y. Yuan, P. Jia, Z. Chen, and H. Li, "Design and Analysis of High Voltage Power Supply for Industrial Electrostatic Precipitators," in Proc. IEEE International Power Electronics Conference, Japan, pp. 3040-3045, May. 2018, doi: 10.23919/IPEC.2018.8507386.

[8] Bhuvaneswari C. and R.S. R. Babu, “Analysis of High voltage High Power Resonant Converters,” International Journal of Power Electronics and Drive System (IJPEDS), vol. 9, no. 1, pp. 174-179, Mar.2018, doi: 10.11591/ijpeds.v9n1.pp.174-179.

[9] S. Zhan, J. Long, Y. Jun, Z. Jianfeng, P. Peng, and Z. Peng, "High Voltage High Power and Medium-frequency Power Transformer Parameters Design," in Proc. IEEE 17th International Conf. on Electrical Machines and Systems (ICEMS), Oct.2014, pp.2449-2453, doi:10.1109/ICEMS.2014.7013917.

[10] A.L. Eshkevari, M. Farzi, and M. Arefian, "Design of a New High-Frequency Power Converter for Electrostatic Precipitators," in Proc. IEEE. Conf. Annual Power Electronics, Drives System Technologies, Feb. 2018, pp. 289-293, doi: 10.1109/PEDSTC.2018.8343811.

[11] S. N. Vukosavić, O. Đorđević, Ž. V. Despotović, and M. Bakić, "Design and Testing of High Voltage High Frequency Transformer $0.6 \mathrm{kV} / 60 \mathrm{kV}$ for Power of $60 \mathrm{~kW}$," in Proc. 18th International Symposium INFOTEH-JAHORINA (INFOTEH), Herzegovina, 20-22 March 2019, pp.1-7, doi: 10.1109/INFOTEH.2019.8717656.

[12] X. Wei, Z. Shen, Y. Ye, J. Leng, Z. Xu, and L. Jin, "Optimization and Design of a High-Voltage Supply for Electrostatic Precipitators," in Proc. IEEE Energy Conversion Congress and Exposition (ECCE)Detroit, MI, USA, Oct. 2020, pp. 2268-2275, doi: 10.1109/ECCE44975.2020.9235595.

[13] Q. Bo, H. Xu, W. Duan, D. Yang, C. Li, and C. Zhu, "Application of Hysteretic Current-Mode Control Technology for Electrostatic Precipitator," in Proc. IEEE International Conference on Electrical Machines and Systems, Australia, Aug. 2017, pp. 343-347, doi: 10.1109/ICEMS.2017.8055980.

[14] Y.-J. Li, and Y.-X. Chen, "Application of High-Voltage Power Supply on Electrostatic Precipitator," World Journal of Engineering and Technology, vol. 5, pp. 269-274, May.2017, doi:10.4236/wjet.2017.52021

[15] S. Fanet et al., "Power Stage and Control Design of a 60-kV 60-kW Switching Power Supply for Industrial Electrostatic Precipitators, in Proc. PCIM Europe, Germany, Jun. 2018, pp. 202-208.

[16] C. Ruttanachot, Y. Tirawanichaku, and P. Tekasaku, "Application of Electrostatic Precipitator in Collection of Smoke Aerosol Particle from Wood Combustion," Aerosol and Air Quality Research, vol. 11, no. 1, pp. 90-98, Feb. 2011, doi:10.4209/aaqr.2010.08.0068.

[17] S.-M. Remaoun, F. Miloua, A. Tilmatine, N. Hammadi, N. Zouzou, and L. Dascalescu, "Optimisation of a Cost-Effective Wire Plate-Type ESP for Installation in a Medical Waste Incinerator,” IEEE Trans. on Industry Application, vol. 50, no. 2, pp. 13911396, Apr.2014, doi:10.1109/TIA.2013.2272607.

[18] N. Grass, and T. Fischer, "High Voltage Power Supply and Control Technologies for Electrostatic Precipitators in Biomass Applications," in Proc. IEEE Industry Application Society Annual Meeting, Oct.2014, pp. 1-4, doi: 10.1109/IAS.2014.6978357.

[19] A. I. Pressman, K. Billings, and T. Morey, Current-mode and Current-fed Topologies: in Switching power supply design, 3rd ed. McGraw Hill, New York,2009.

[20] H. Nouri, I.E. Achouri, H. A. Said, and M. Aissou, "Least Squares method identification of Corona Current-Voltage Characteristics and Electromagnetic Field in Electrostatic Precipitator," International Journal of Electrical, Computer, Energetic, Electronic and Communication Engineering, vol. 9, no. 12, Jan. 2015, pp. 1282-1287. 
[21] N. Cid, J.J. Rigo, R. Perez-Orozco, and A. Larranaga, "Experimental Study of the Performance of a Laboratory-Scale ESP with biomass Combustion: Discharge Electrode Disposition, Dynamic Control Unit and Aging Effect,” Sustainability, vol. 13, no. 18, pp. 1-11, 2021, doi:10.3390/su131810344.

[22] D. F. Johnston, J. A. Knapik, and J. Walker, "Taking the Mystery out of Choosing Electrostatic Precipitator Power supplies for MATS PM Control," in Proc Power Plant Pollutant Control MEGA Symposium, Baltimore, USA, pp. 1-15, Aug.2014.

[23] W. Gao et al., "A Numerical Investigation of the Effect of Dust Layer on Particle Migration Electrostatic precipitator," Aerosol and Air Quality Research, vol. 20, pp. 166-179, 2020, doi:10.4209/aaqr.2019.11.0609.

[24] A. F. Altun and Mn Kilic, "Utilisation of Electrostatic Precipitators for healthy indoor environments," in Proc.E3S Web of Conferences 111, Jan.2019, pp.1-7, doi:10.1051/e3sconf/201911102020.

[25] A. Swierczok and M. Jedrusik, "The collection efficiency of ESP model-Comparison of experimental results and calculations using Deutsch model," Journal of Electrostatics, vol. 91, pp. 41-47, 2018, doi: 10.1016/j.elstat.2017.12.004.

\section{BIOGRAPHIES OF AUTHORS}

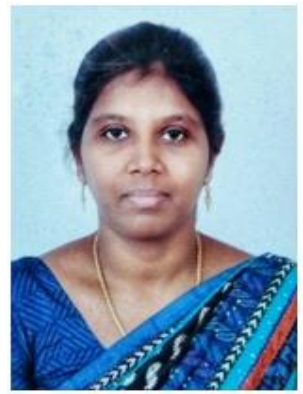

Beula David (D) SC SC P received the B.E degree in the field of Electrical and Electonics Engineering from Madurai Kamaraj University, India in the year 1994 and ME in Power Systems from Annamalai University, India in 1997. Currently, she is working as Associate Professor in the department of Electrical Engineering at Sir. M. Visvesvaraya Institute of Technology, Bengalore, India. She has 20 years of teaching experience in Engineering colleges. Her area of interest is in the field of power converters and power systems. She can be contacted at email: beula.d2014@gmail.com.

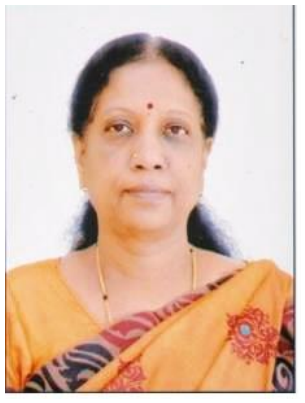

Indira Megaravalli Shankarappa (iD $\mathrm{SC}$ SC $\mathrm{P}$ graduated from Bangalore University in Electrical Engineering. She obtained both postgraduate and Doctorate degrees from Indian Institute of Science (IISc) in High Voltage Engineering, Bangalore, India. She is currently the Associate Dean Academic Affairs, M S Ramaiah University of Applied Science, Bangalore. Her areas of interest are Power System Engineering and High voltage Engineering. She has several publications, funded projects to her credit and co-authored a book on CAD for Electrical Engineers. She can be contacted at email: indirams@yahoo.com.

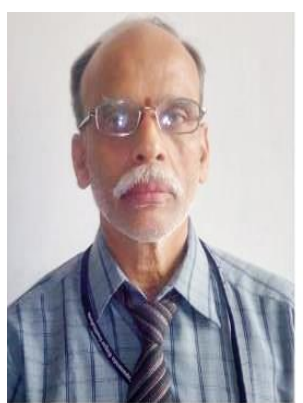

Balaji Nerayanur (D) SC $\mathrm{SC}$ received the B.Tech degree from the Regional College of Engineering, Warangal,India, in the field of Electrical in 1978, M.Tech degree from the Regional College of Engineering, Warangal, India, in the field of Electrical in 1981 and completed his Ph.D. in the field of Power Electronics in the year 2013. She has 19 years of teaching experience in Engineering Colleges. He also has vast industrial experience of over 20 years including the one as Senior Manager in NGEF Ltd, Bangalore. His area of Interest/Research is Power Electronics- Drives and Power Supplies. Apart from his numerous years of experience in the Teaching and Administrative field, Dr. Balaji has also guided numerous projects at the UG, Masters and Ph.D levels. He can be contacted at email: drbalajin@gmail.com. 